\title{
Reuna
}

\section{A EDUCAÇÃO COMO INSTRUMENTO DE CONTROLE SOCIAL E MONITORAMENTO DA TRANSPARÊNCIA FISCAL}

\section{THE EDUCATION AS INSTRUMENT OF SOCIAL CONTROL}

\author{
http://dx.doi.org/10.21714/2179-8834/2019v24n4p22-43
}

\author{
Celia Regina Pereira da Silva \\ Fucape Business School, Brasil. \\ E-mail: crsilva2812@gmail.com \\ Neyla Tardin \\ Fucape Business School, Brasil. \\ E-mail: neyla@fucape.br
}

Submissão: 23 Nov. 2018 Publicação: 19 Dez. 2019. Sistema de avaliação: Double blind review. Centro Universitário UNA, Belo Horizonte - MG, Brasil. Editor geral: Prof. Dr. Gustavo Quiroga Souki

Este artigo encontra-se disponível nos seguintes endereços eletrônicos:

http://revistas.una.br/index.php/reuna/article/view/1054

http://dx.doi.org/10.21714/2179-8834/2019v24n4p22-43

\section{Resumo}

A Transparência Fiscal é uma ferramenta para acompanhar e monitorar o desempenho da gestão pública. Nesse contexto, a presente pesquisa teve por objetivo avaliar se os níveis de educação da população, como instrumento de controle e participação social, influenciaram os indicadores de Transparência Fiscal dos Estados brasileiros. Os efeitos do estudo evidenciaram que os níveis educacionais dos Estados brasileiros apresentaram associação positiva com a transparência fiscal, sugerindo que a população mais educada demanda por mais informações, o que força os governos a divulgarem mais e melhores informações, indicando que onde há altos níveis educacionais é de se esperar uma transparência fiscal maior e mais forte. $\mathrm{O}$ nível educacional da população, com enfoque no grau de instrução, mostrou-se significativo para explicar os níveis de Transparência Fiscal dos estados brasileiros por sugerir que a sociedade mais crítica e consciente dos seus direitos tende a gerar pressões nos governos para cumprir com suas obrigações.

Palavras-chave: Transparência Fiscal, Educação, Controle social. 


\section{Abstract}

The Fiscal Transparency is a tool to accompany the performance of public management. In this context, the present research had the objective of evaluating whether the levels of education of the population, as an instrument of control and social participation, influenced the Fiscal Transparency indicators of the Brazilian states. The effects of the study showed that the educational levels of the Brazilian states were positively associated with fiscal transparency, suggesting that the more educated population demand more information, which forces governments to divulge more and better information, indicating that where there are high levels of education greater and stronger fiscal transparency is to be expected. The educational level of the population, with a focus on education, has been significant in explaining the levels of Fiscal Transparency in the Brazilian states, suggesting that the most critical and conscientious society of their rights tends to generate pressure on governments to fulfill their obligations institutions.

Keywords: Fiscal Transparency. Education. Social control..

\section{Introdução}

O cidadão, como titular do poder, tem direito de monitorar seus governantes, com o objetivo de evitar o mau uso e o desperdício do dinheiro público (SOL, 2013; RIBEIRO; ZUCCOLOTTO, 2014). Nesse contexto, a transparência fiscal, definida como o conjunto de instrumentos legais que promovem o acesso e exigem a divulgação de informações confiáveis e tempestivas a todos os interessados (TEJEDO-ROMERO; ARAUJO,2018; SOL, 2013), apresenta-se como uma ferramenta útil para avaliar o desempenho dos agentes públicos (SOL, 2013; ZUCCOLOTTO; TEIXEIRA, 2017). Um Estado com as finanças públicas transparentes torna-se capaz de implementar melhorias constantes nos seus sistemas de governança, em conjunto com a sociedade (CRUZ et al., 2016; SOL, 2013).

Estudos anteriores abordaram os determinantes dos níveis de transparência fiscal, ora com ênfase em fatores políticos - a exemplo da força que um partido ou coalizão política exerce sobre a opinião pública -, ora com foco em fatores socioeconômicos e macroeconômicos - a exemplo do gênero do eleitor, da renda das famílias, da saúde, da educação e do grau de desenvolvimento do país (TEJEDO; ARAUJO, 2018; ARAÚJO; TEJEDO, 2016; GUILLAMÓN; BATISTA; BENITO, 2011; SOL, 2013; ZUCCOLOTTO; TEIXEIRA, 2014; RIBEIRO; ZUCCOLOTTO, 2014; BERNARDO; REIS; SEDIYAMA, 2017; CRUZ et al., 2012). Esses fatores são evidências de que apenas a força de uma legislação específica, como a Lei de Responsabilidade Fiscal brasileira, não é suficiente para explicar a transparência fiscal (MOTA; DINIZ; SANTOS, 2017; SOL, 2013; ZUCCOLOTTO; TEIXEIRA, 2014).

Em linha com essas evidências, o presente estudo tem por objetivo investigar se e como os níveis educacionais da população, instrumento indireto de controle da gestão pública, estão associados ao grau de transparência fiscal dos estados brasileiros. A capacidade de monitorar os agentes públicos, por meio de instrumentos de transparência fiscal, está intimamente relacionada com o nível de escolaridade da população, de modo que essa condição capacita e habilita os cidadãos ao 
entendimento dos dados disponibilizados pelos entes públicos (PIORTROWSKI; VAN RYZIN, 2007), tornando-os aptos a monitorar a gestão dos recursos públicos.

Para testar a hipótese de que o grau de escolaridade da população afeta positivamente no grau de transparência fiscal dos estados brasileiros foi realizada uma regressão linear múltipla, com estimação via mínimos quadrados ordinários. Diferentemente de outros estudos sobre o tema, o nível educacional é mensurado não por meio dos investimentos e dos gastos na área da educação (RIBEIRO; ZUCCOLOTTO; 2014), nem por meio do Índice de Desenvolvimento Humano - IDH educacional (TEIXEIRA; ZUCCOLOTTO, 2014), mas utilizando-se variáveis educacionais relativas à população adulta, com enfoque no grau de instrução, como instrumento para o controle social e melhoria da transparência fiscal

Os resultados desta pesquisa mostraram que fatores educacionais afetam positivamente na transparência fiscal, evidenciando que a população com maior grau de escolaridade demanda por mais informações, o que força os Governos a divulgarem mais e melhores informações, afirmando que onde há altos níveis educacionais é de se esperar uma transparência fiscal maior e mais forte. (TOLBERT; MOSSBERGER; MACNEAL, 2008; ALT et al., 2006). O desenvolvimento educacional gera uma sociedade crítica e consciente dos seus direitos e de suas obrigações, o que pressiona os Governos a manterem os bons níveis dos serviços prestados (TEIXEIRA; ZUCCOLOTTO, 2014).

Como proxy para a transparência fiscal, foi utilizado o Índice de Transparência Fiscal - ITF, coletado da ONG Contas Abertas. Esse índice é fundamentado em parâmetros técnicos e legais, quanto ao conteúdo, a séries históricas e à usabilidade dos portais de transparência, com ênfase nas informações sobre a execução orçamentária dos órgãos em relação ao cumprimento da legislação das receitas e despesas, às regras relacionadas aos procedimentos licitatórios. O índice também considera o volume e a qualidade de divulgação de relatórios, bem como a interação e a usabilidade da população quanto aos itens divulgados. O ITF, por fim, consiste em um ranking de notas, variando de 0 a 10, com o objetivo de classificar os entes públicos com maior ou menor grau de transparência, disponível para o período de 2010 a 2014. (INDICE DE TRANSPARÊNCIA, 2014).

A Transparência Fiscal é um instrumento que melhora a qualidade da gestão pública, aumentando a eficácia dos resultados, o controle dos atos e a responsabilização eficaz dos agentes públicos, além de melhorar a compreensão dos cidadãos acerca das políticas públicas (TEJEDO-ROMERO; ARAÚJO,2018; CELLA; ZANOLLA, 2018; MONTES;BASTOS; OLIVEIRA, 2019)). A ausência de transparência está comumente associada à corrupção governamental, por permitir a omissão de informações e mascarar os interesses dos agentes públicos (GUILLAMÓN; BATISTA; BENITO, 2011; CELLA; ZANOLLA, 2018; SIMONE; GAETA; MOURÃO, 2017).

Este estudo contribui com a literatura ao reforçar a necessidade prática de investimentos em políticas públicas educacionais efetivas que melhorem a qualidade do ensino, com o objetivo de capacitar os cidadãos ao exercício do controle social, evitando-se o mau uso e o desperdício de recursos públicos. Para a academia, os resultados apresentados mostraram a relevância da educação como atributo necessário ao perfil dos cidadãos para a compreensão da Transparência Fiscal e a consequente participação no processo democrático do país. 
Este estudo está estruturado em cinco capítulos, a contar desta introdução, passando pela revisão da bibliografia, seguida pela metodologia aplicada ao desenvolvimento da pesquisa, pela análise e discussão dos dados até as conclusões.

\section{Referencial teórico}

\subsection{Transparência fiscal}

O estudo da transparência é uma temática que vem crescendo ao longo dos anos na literatura internacional, cujas tentativas de entendimento direcionaram-se na perspectiva de que o aumento da transparência melhora a qualidade dos entes públicos e traz mais confiança e bons desempenhos financeiros (CUCCINIELLO; PORUMBESCU; GRIMMELIKHUIJSEN, 2017; GRIMMELIKHUIJSEN; MEIJER, 2012; MEIJER, 2015).

Tejedo-Romero e Araújo (2018) indicam que a transparência é um instrumento para melhorar a qualidade da gestão pública, aumentando a eficácia dos resultados, o controle da corrupção e a responsabilização eficaz dos agentes públicos sobre seus atos, além de melhorar a compreensão dos cidadãos acerca das políticas públicas. A falta da transparência está comumente associada à corrupção governamental (GUILLAMÓN; BATISTA; BENITO, 2011).

Paiva e Zuccolotto (2009) informam que, no Brasil, o embrião da transparência nasceu com a Constituição Federal de 1988, com o estabelecimento da publicidade como princípio da Administração Pública, a partir do qual o Governo passa a ser obrigado a divulgar todos os seus atos. As implicações legais da transparência foram impulsionadas pela edição da Lei de Responsabilidade Fiscal - LRF (Lei no 101/2000), pela Lei de Transparência (Lei no 131/2009) e pela Lei de Acesso à Informação - LAI (Lei no 12.527/2011) (CRUZ et al., 2012; JAHNS; RAUPP, 2016; MOTA; DINIZ; SANTOS, 2017).

Apesar dos esforços legais e institucionais para sedimentarem a transparência pública como instrumento de democracia, controle e participação social, estudos evidenciaram o seu estágio inicial de desenvolvimento, haja vista os contextos políticos e culturais influenciarem o seu contexto prático (CRUZ et al., 2012; RIBEIRO; ZUCCOLOTTO, 2014; BERNARDO; REIS; SEDIYAMA, 2017).

\section{2 Índice de Transparência Fiscal}

$\mathrm{Na}$ intenção de entender e medir a transparência governamental, estudos nacionais e internacionais procuraram desenvolver índices que servissem de fonte para aferir o nível de transparência (PAIVA; ZUCCOLOTTO, 2009; BAIRRAL; SILVA; ALVES, 2015; CRUZ et al., 2016; BERNARDO; REIS; SEDIYAMA; 2017).

Cruz et al. (2016), por meio de informações disponíveis nos sites oficiais do Governo local, desenvolveram um Índice de Municipal de Transparência (IMT), baseado em métodos que permitiam a participação popular, para dimensionar indicadores de transparência. A aplicação desse índice foi testada em municípios portugueses e permitiu a publicação de um ranking de transparência que, conforme os autores, poderia gerar pressão para que os governos locais se ajustassem ao indicador. 
Estudos sobre a transparência, na Espanha, utilizaram um índice desenvolvido pela organização não governamental Transparency International Spain (GUILLAMÒN; BATISDA; BENITO, 2011; SOL, 2013; TEJEDO-ROMERO; ARAUJO,2018). Esse índice, desenvolvido pela ONG Transparency International Spain, fora utilizado nos estudos para identificar os fatores sociais, políticos e econômicos determinantes na Transparência Fiscal (GUILLAMÒN; BATISDA; BENITO, 2011; SOL, 2013; TEJEDOROMERO; ARAUJO, 2018).

No Brasil, Paiva e Zuccolotto (2009) elaboram um indicador para medir o nível de Transparência Fiscal nos municípios via Web, baseado em critérios de quantidade e qualidade de informações divulgadas. $O$ indicador foi aplicado numa amostra de 275 municípios do estado de Minas Gerais, onde se constatou que 75,27\% dos municípios mineiros apresentaram baixa transparência fiscal quanto ao volume de informações disponíveis na internet para o controle dos cidadãos.

A Organização não Governamental (ONG) Contas Abertas, fundamentada na LRF, elaborou um instrumento de medida para aferir a transparência fiscal, que contemplava informações sobre conteúdo, séries históricas e usualidade dos portais de transparência dos entes governamentais (ABREU; GOMES; ALFINITO, 2015). O Índice de Transparência Fiscal (ITF), desenvolvido pela ONG Contas Abertas, com base em parâmetros técnicos e legais, consiste em um ranking de notas, com vistas a identificar os entes públicos com maior ou menor grau de transparência (INDICE DE TRANSPARÊNCIA, 2014).

O índice da ONG Contas Abertas fora utilizado no estudo de Zuccolotto e Teixeira (2015) para analisar a relação entre a participação social no aprimoramento da democracia, por meio dos instrumentos de transparência dos estados brasileiros. Serviu como instrumento que norteou o estudo comparativo entre os portais de transparência dos municípios gaúchos de Pelotas e Porto Alegre para que sejam considerados como transparentes (LIMA et al., 2015).

\subsection{Transparência fiscal e as variáveis socioeconômicas}

Visando identificar os fatores que poderiam influenciar os níveis de transparência, vários estudos buscaram relacionar a transparência a fatores externos à gestão, tais como variáveis na área política, financeira, econômica e social (GUILLAMÒN; BASTIDA; BENITO, 2011; RIBEIRO; ZUCCOLOTTO, 2014; TEJEDOROMERO; ARAUJO, 2018; SOL, 2013; BAIRRAL; SILVA; ALVES, 2015; MOTA; DINIZ; SANTOS, 2017; CRUZ et al., 2012; TEIXEIRA; ZUCCOLOTTO, 2014; BERNARDO; REIS; SEDIYAMA, 2017; ARAUJO; TEJEDO-ROMERO, 2016).

Tejedo-Romero e Araújo (2018) identificaram que a transparência fiscal está associada a fatores econômicos e políticos, mostrando que a taxa de desemprego, gênero, participação eleitoral e força política apresentou significância nos níveis de transparência nos municípios da Espanha, quando analisados no período de 2008 a 2012, evidenciando os fatores políticos como os mais relevantes na associação. Bearfield e Bowman (2017) corroboram desse entendimento ao afirmarem que em ambientes com altos níveis de competição política maior valor é dado ao cidadão, devido a sua capacidade de acessar às informações, implicando na melhora da transparência, dado que a informação é um fator de convencimento da população.

Araújo e Tejedo-Romero (2016) concluíram que o tamanho da população e o desemprego mudaram a relação da transparência com fatores políticos, justificando 
que populações maiores demandam mais de seus governantes e que, em tempos de crise, o desemprego aumenta, diminuindo o status econômico dos municípios e, consequentemente, o status da transparência. Sol (2013) também constatou a influência do tamanho da população, afirmando que grandes municípios tendem a divulgar melhores índices de transparência.

No trabalho de Guillamòn, Batista e Benito (2011), as variáveis socioeconômicas Renda per capita, População e Dívida per capita mostraram-se relevantes quando estudadas nos 100 maiores municípios da Espanha, no ano de 2008, quando relacionadas com o nível de transparência, apontando que, quanto maior a arrecadação de impostos e transferências per capita, maiores as informações financeiras divulgadas.

Ribeiro e Zuccolotto (2014) também conseguiram constatar relação entre a transparência fiscal e as variáveis socioeconômicas numa amostra de 1678 municípios brasileiros, ao identificarem que os fatores saúde, educação, emprego e renda per capita mostram interações positivas com os níveis de transparência, confirmando a alternativa de que municípios com melhor arrecadação de receitas públicas, investimentos em educação e saúde, bem como desenvolvimento social e humano, serão capazes de proporcionar maior transparência para a população.

Cruz et al. (2012) encontraram relação entre os fatores socioeconômicos e a transparência fiscal a partir da análise dos 100 maiores municípios brasileiros, mas evidenciaram que os índices de transparência eram incompatíveis com o grau de desenvolvimento socioeconômico apresentado pelos municípios, pois, embora apresentassem um bom desenvolvimento, a transparência mostrava-se baixa.

Os achados dos estudos anteriores revelam que a transparência fiscal é influenciada por fatores socioeconômicos. O Quadro 1 apresenta o resumo das variáveis socioeconômicas que foram analisadas nos estudos de relação com a transparência fiscal:

\section{Quadro 1.Variáveis Demográficas e Socioeconômicas}

\begin{tabular}{|l|l|}
\hline \multicolumn{1}{|c|}{ Variáveis estudadas } & \multicolumn{1}{|c|}{ Autores } \\
\hline Taxa de desemprego, gênero, participação eleitoral e força política & $\begin{array}{l}\text { Tejedo-Romero e Araújo } \\
\text { (2018) }\end{array}$ \\
\hline Renda per capita, população e dívida per capita & $\begin{array}{l}\text { Guillamòn; Batista e Benito } \\
\text { (2011) }\end{array}$ \\
\hline $\begin{array}{l}\text { Fatores saúde, educação, emprego, renda e receita pública per } \\
\text { capita }\end{array}$ & Ribeiro e Zuccolotto (2014) \\
\hline $\begin{array}{l}\text { Índice de Consumo (IPC), PIB per capita, Desenvolvimento } \\
\text { Humano, índices de Alfabetização, Îndice Firjan Municipal, Índice de } \\
\text { gestões Fiscais e Sociais dos municípios }\end{array}$ & Cruz et. al., (2012) \\
\hline $\begin{array}{l}\text { Gênero, idade, variáveis fiscais dívida, desemprego, economia ativa, } \\
\text { turismo }\end{array}$ & Sol (2013) \\
\hline $\begin{array}{l}\text { IFDM saúde, educação, emprego e renda; gastos per capita com } \\
\text { educação e saúde; receita per capita. }\end{array}$ & Teixeira e Zuccoloto (2014) \\
\hline $\begin{array}{l}\text { Receitas de Transferências, Gastos com Saúde, Receita Própria per } \\
\text { capita, Gasto com Pessoal e educação }\end{array}$ & Mota; Diniz e Santos (2017) \\
\hline $\begin{array}{l}\text { Participação eleitoral, Ideologia política, Competição política, } \\
\text { Tamanho da população e Desemprego }\end{array}$ & $\begin{array}{l}\text { Araújo e Tejedo - Romero } \\
\text { (2016) }\end{array}$ \\
\hline
\end{tabular}

Fonte: Adaptado de Tejedo-Romero e Araújo (2018); Guillamòn, Batista e Benito (2011); Ribeiro e Zuccolotto (2014); Cruz et al., (2012); Sol (2013); Teixeira e Zuccoloto (2014); Mota, Diniz e Santos (2017); Araújo e Tejedo - Romero (2016) 


\subsection{Controle social e nível de educacional}

O controle social, exercido pela participação popular efetiva, depende fortemente das ações de transparência desenvolvidas pelos governos e agentes públicos, pois sem o devido conhecimento das informações, a população deixa ou diminui a sua participação social (FIGUEREDO; SANTOS, 2013). Segundo Platt Neto et al. (2007), a transparência é essencial para o exercício desse controle, evidenciando uma política governamental responsável que beneficia o aprendizado e o desenvolvimento da cidadania, sem a qual as decisões sociais ficam prejudicadas

Para Bairral, Silva e Alves (2015), a transparência fiscal proporciona uma melhor participação social, estreitando o entendimento entre a sociedade e o Estado, corroborando para o aprimoramento da noção de responsabilidade dos gestores públicos e, consequentemente, para a responsabilização de seus atos. Aumento de transparência aproxima o cidadão e o gestor público, estimula a participação democrática e a confiança no Governo (BERTOT; JAEGER; GRIMES, 2010; MEIJER, 2013; BAIRRAL; SILVA; ALVES, 2015; PORUMBESCU, 2017).

Borges e Pereira (2014) informam que essa participação social precisa ser estimulada para que o cidadão possa desenvolver o exercício pleno da cidadania, de forma que venha a conhecer do processo de elaboração, aplicação e da avaliação dos programas e das políticas públicas do Governo. Figueiredo e Santos (2013) asseveram a importância de preparar o cidadão para o controle social, uma vez que, treinado de forma adequada, poderá usufruir das ferramentas de transparência disponíveis para o seu conhecimento.

O grau de participação dos cidadãos no processo de transparência perpassa pelo nível de compreensão e pelo entendimento das informações que, por sua vez, prescinde do nível de educação da sociedade (BORGES; PEREIRA, 2014). A capacidade de conhecimento e de compreensão das informações divulgadas assente aos cidadãos participação na gestão e no controle da Administração Pública, indicando uma administração pública transparente, haja vista que a compreensão do que está sendo divulgado é essencial para classificar uma informação como transparente (FIGUEREDO; SANTOS, 2013).

A transparência implica um diálogo eficaz entre as partes interessadas, com linguagem adequada, capaz de possibilitar o acesso às informações que, para serem úteis, precisam ser relevantes, confiáveis e compreensíveis aos seus usuários, fato que depende do nível de compreensão e do grau de escolaridade dos cidadãos (CORBARI, 2014). Figueiredo e Santos (2013) afirmam que os usuários da informação precisam assimilar o que está sendo divulgado: uma informação é dita transparente quando puder atender a esse objetivo - a compreensibilidade. As escolas precisam adequar-se a essas novas demandas de preparar os cidadãos à participação social e ao exercício da cidadania (FIGUEREDO; SANTOS, 2013; RODRIGUES, 2001).

Piortrowski e Van Ryzin (2007) destacam a importância da relação do nível de escolaridade da sociedade com a sua participação social e a do grau de confiança no Governo com a consequente demanda por mais transparência. Os autores explicam o fato de como um diploma de nível superior habilita e capacita o cidadão ao entendimento da burocracia, dando-Ihe segurança para solicitar informações ao Governo. 
A educação é o instrumento que prepara o cidadão para agir na esfera pública, associando-o ao processo civilizatório que possibilita a liberdade de expressão e de opinião, colaborando para o desenvolvimento de uma sociedade participativa e de consciência política com habilidades para participar do debate público (BARROS, 2016; DAHLUM; KNUTSEN, 2017). A educação ensina as pessoas a interagirem umas com as outras, melhorando suas habilidades e capacidades cognitivas e, consequentemente, aumentando o processo de participação social (GLAESER; PONZETTO; SHLEIFER, 2007; DAHLUM KNUTSEN, 2017).

Na pesquisa de Teixeira e Zuccolotto (2014), sobre as causas fiscais, sociais e políticas determinantes da transparência dos entes estaduais, dentre os vários resultados identificou que melhores condições educacionais revelaram maior transparência fiscal, justificada pelo fato de que a melhora no nível educacional da população leva ao desenvolvimento de uma sociedade crítica e consciente dos seus direitos e de suas obrigações, o que pressiona os governos a manterem os bons níveis dos serviços prestados. A melhoria da percepção dos benefícios gerados leva a melhores indicadores sociais, dentre os quais se destaca o desenvolvimento educacional da população, que tem relação positiva com os níveis de transparência (RIBEIRO; ZUCCOLOTTO, 2014).

Ribeiro e Zuccolotto (2014), em estudo sobre as determinantes socioeconômicas e fiscais da transparência fiscal, certificaram que pessoas com maior nível educacional tendem a ter melhores condições sociais e cobram mais de seus governantes a permanência dessa situação. Além disso, os autores destacam que governos com bons resultados nessa área buscam constantemente validar suas boas administrações, divulgando seus bons desempenhos.

Lindstedt e Naurin (2010) afirmaram que o nível de educação pode influenciar na relação entre cidadãos e Estado, uma vez que quanto maior o nível educacional, maior a capacidade das pessoas para acessar e processar as informações divulgadas. Os autores constataram, em sua pesquisa sobre corrupção em países desenvolvidos e subdesenvolvidos, que quanto mais crescentes os níveis educacionais, maior o efeito da transparência sobre a corrupção, indicando que reformas para promover a capacidade das pessoas de acessar e processar informações reduz a corrupção.

Estudos anteriores constataram que a educação teve efeito positivo na transparência e demonstraram que a população mais escolarizada demanda por mais informações, o que força os governos a divulgarem mais e melhores as informações, afirmando que onde há altos níveis educacionais é de se esperar uma transparência fiscal maior e mais forte. (TOLBERT; MOSSBERGER; MACNEAL, 2008; ALT et al., 2006). Aquiles, Galera e Rodrigues (2014) corroboram esse entendimento ao identificarem uma relação positiva entre a transparência e o nível educacional, argumentando que maiores níveis educacionais estimulam a demanda por mais informações.

Assim, com o objetivo de analisar os fatores educacionais como ferramenta de controle social na relação com a transparência fiscal no contexto dos estados brasileiros, a presente pesquisa verificou a seguinte hipótese:

H1: O nível educacional da população, como ferramenta de monitoramento social, afeta positivamente os índices de Transparência Fiscal dos estados brasileiros 


\section{Metodologia}

\subsection{Amostra: coleta e tratamento dos dados}

O objetivo deste trabalho foi identificar se as variáveis educacionais explicam os níveis de transparência fiscal dos 26 estados brasileiros e do Distrito Federal, vistos como os entes responsáveis por assegurar o Ensino Fundamental e proporcionar, com preferência, o Ensino Médio no país, conforme inciso VI do art. 10 da Lei de Diretrizes e Bases da Educação Nacional - Lei no 9.394, de 20 de dezembro de 1996.

Para atender ao objetivo proposto, foi realizada uma pesquisa quantitativa, com dados secundários e corte transversal, referente ao período de 2010 a 2014, período disponível da variável dependente Índice de Transparência Fiscal dos estados brasileiros, com dados obtidos junto à ONG Contas Abertas e junto ao Atlas do Desenvolvimento Humano no Brasil, para as variáveis independentes, fundamentado nos dados do Instituto Brasileiro de Geografia e Estatística - IBGE.

Como variável dependente $(Y)$, foi definido o Índice de Transparência Fiscal ITF, e como independentes $(\mathrm{X})$, foram definidas as variáveis educacionais relativas à população adulta: Anos de Estudo, Frequência ao Nível Superior, Taxa de Ensino Médio Completo, Taxa de Ensino Superior Completo e Desenvolvimento Humano Educação. Como controles, foram utilizadas as variáveis Renda per capita, Índice GINI, PIB, População e Força Política, citadas na literatura e definidas adiante.

O tamanho da população, por exemplo, altera o status da transparência, pois populações maiores tendem a demandar por mais informações (ARAUJO; TEJEDOROMERO, 2016); assim como maior arrecadação de imposto, devido à renda per capita, exigem maior quantidade de informações financeiras divulgadas (GUILLAMÒN; BATISTA; BENITO, 2011). A Força Política, no estudo de TejedoRomero e Araújo (2018), foi utilizada para identificar se alianças políticas no Governo ou partidos com maioria absoluta gerariam pressões para ser mais transparente.

No estudo de Cruz et al. (2012) acerca da Transparência da Gestão Pública Municipal, o PIB per capita fora utilizada como variável socioeconômica para explicar a transparência fiscal dos portais eletrônicos dos entes municipais. O Índice GINI, que mede a igualdade ou a desigualdade no nível de distribuição de renda, foi evidenciado como variável explicativa do nível de transparência fiscal da Administração Pública no estudo de Bernardo, Reis e Sediyama (2017).

\subsection{Descrição das variáveis}

\subsection{1 Índice de Transparência Fiscal Estadual}

Para a variável dependente Índice de Transparência Fiscal optou-se por utilizar o índice divulgado pela ONG Contas Abertas para os Estados brasileiros, conforme se observa no Quadro 2. 
Quadro 2. Variável Dependente e Índices de Transparência Fiscal

\begin{tabular}{|c|l|l|c|c|}
\hline \multicolumn{2}{|c|}{ Variável } & \multicolumn{1}{|c|}{ Descrição da variável } & Fonte & Cálculo \\
\hline ITF & $\begin{array}{l}\text { Índice de } \\
\text { Transparência } \\
\text { Fiscal - ITF }\end{array}$ & $\begin{array}{l}\text { Mede o nível de Transparência divulgado } \\
\text { pelos Estados da Federação, } \\
\text { apresentando um ranking entre os } \\
\text { Estados mais transparentes, período de } \\
2010 \text { a 2014 }\end{array}$ & $\begin{array}{c}\text { ONG - Contas } \\
\text { Abertas }\end{array}$ & $\begin{array}{c}\text { Variável } \\
\text { numérica } \\
\text { (números } \\
\text { absolutos) }\end{array}$ \\
\hline
\end{tabular}

Fonte: Adaptado do ranking de Transparência Fiscal da ONG Contas Abertas,

O Índice de Transparência Fiscal, disponível para os exercícios 2010 a 2014, foi desenvolvido com base em estudos internacionais e na Lei oㅜ 131/2009 - Lei de Transparência -, que mede as características dos portais de transparência dos estados quanto ao conteúdo, séries históricas e frequência de atualização e usabilidade, conforme se percebe no Anexo 1, criando um ranking de notas, variando de 0 a 10, relacionando os estados mais transparentes, de acordo com a adequação aos critérios de avaliação.

O Índice de Transparência Fiscal - ITF traz informações relativas à execução orçamentária dos órgãos públicos quanto ao cumprimento da legislação das receitas e despesas públicas, bem como se relacionam aos procedimentos licitatórios, à divulgação de relatórios e a interação e usabilidade da população quanto aos itens divulgados pelos entes, em obediência aos instrumentos normativos que exigem o cumprimento da Transparência Fiscal

\subsubsection{Variáveis Independentes}

As variáveis independentes são as variáveis educacionais disponíveis no Atlas do Desenvolvimento Humano no Brasil. Elas abrangem o Atlas do IDH nos Municípios e o Atlas do IDH nas Regiões Metropolitanas, formando uma base de consulta ao Índice de Desenvolvimento Humano Municipal, das Unidades da Federação, suas Regiões Metropolitanas e demais Regiões Integradas de Desenvolvimento, fundamentado em dados do Instituto Brasileiro de Geografia e Estatística - IBGE (Atlas Brasil, 2013).

As variáveis sobre a educação foram as relativas à população adulta, que representa a parcela da população que seria economicamente ativa e apta ao exercício da cidadania e à fiscalização efetiva dos governos, correspondentes aos exercícios 2010 a 2014, com as descrições apresentadas no Quadro 3. 
Quadro 3. Variáveis Independentes

\begin{tabular}{|c|c|c|c|c|c|}
\hline \multicolumn{3}{|c|}{ Variável } & \multirow{2}{*}{\begin{tabular}{|l|}
\multicolumn{2}{|c|}{ Descrição } \\
Razão entre o somatório do \\
número de anos de estudo \\
completos das pessoas \\
nessa faixa etária e o total \\
dessas pessoas. \\
\end{tabular}} & \multirow[b]{2}{*}{$\begin{array}{c}\text { Fonte } \\
\text { Atlas } \\
\text { Brasil } \\
2010 \text { a } \\
2014\end{array}$} & \multirow{2}{*}{$\begin{array}{l}\text { Cálculo } \\
\text { Numérica }\end{array}$} \\
\hline $\mathrm{X} 1$ & Anos de Estudo & \begin{tabular}{|c|} 
Média de anos de \\
estudo das \\
pessoas de 25 \\
anos ou mais de \\
idade
\end{tabular} & & & \\
\hline $\mathrm{X} 2$ & $\begin{array}{l}\text { Frequência ao } \\
\text { Ensino Superior }\end{array}$ & $\begin{array}{c}\text { Taxa de } \\
\text { frequência ao } \\
\text { ensino superior }\end{array}$ & $\begin{array}{l}\text { Razão entre o número de } \\
\text { pessoas na faixa etária de } \\
18 \text { a } 24 \text { anos frequentando } \\
\text { o ensino superior } \\
\text { (graduação, especialização, } \\
\text { mestrado ou doutorado) e a } \\
\text { população total dessa } \\
\text { mesma faixa etária, } \\
\text { multiplicada por } 100 \text {. }\end{array}$ & $\begin{array}{l}\text { Atlas } \\
\text { Brasil } \\
2010 \text { a } \\
2014\end{array}$ & Taxa decimal \\
\hline X3 & $\begin{array}{l}\text { Taxa Ensino } \\
\text { Médio Completo }\end{array}$ & $\begin{array}{c}\text { Percentual da } \\
\text { população de } 18 \text { a } \\
20 \text { anos de idade } \\
\text { com o ensino } \\
\text { médio completo }\end{array}$ & $\begin{array}{l}\text { Razão entre a população de } \\
18 \text { a } 20 \text { anos de idade que } \\
\text { já concluiu o ensino médio } \\
\text { em qualquer de suas } \\
\text { modalidades (regular } \\
\text { seriado, não seriado, EJA } \\
\text { ou supletivo), o o total de } \\
\text { pessoas nesta faixa etária, } \\
\text { multiplicada por } 100 \text {. As } \\
\text { pessoas de } 18 \text { a } 20 \text { anos } \\
\text { frequentando a } 4^{a} \text { série do } \\
\text { ensino médio foram } \\
\text { consideradas como já tendo } \\
\text { concluído esse nível de } \\
\text { ensino. }\end{array}$ & $\begin{array}{l}\text { Atlas } \\
\text { Brasil } \\
2010 \text { a } \\
2014\end{array}$ & Taxa decimal \\
\hline X4 & $\begin{array}{l}\text { Taxa de Ensino } \\
\text { Superior Completo }\end{array}$ & $\begin{array}{l}\text { Percentual da } \\
\text { população de } 25 \\
\text { anos ou mais com } \\
\text { superior completo }\end{array}$ & $\begin{array}{l}\text { Razão entre a população de } \\
25 \text { anos ou mais de idade } \\
\text { que concluiu pelo menos a } \\
\text { graduação do ensino } \\
\text { superior e o total de } \\
\text { pessoas nesta faixa etária, } \\
\text { multiplicada por } 100 \text {. }\end{array}$ & $\begin{array}{c}\text { Atlas } \\
\text { Brasil } \\
2010 \text { a } \\
2014\end{array}$ & Taxa decimal \\
\hline$\times 5$ & $\begin{array}{l}\text { Desenvolvimento } \\
\text { Humano - } \\
\text { Educação }\end{array}$ & $\begin{array}{c}\text { Índice de } \\
\text { Desenvolvimento } \\
\text { Humano Municipal } \\
\text { - Dimensão } \\
\text { Educação }\end{array}$ & $\begin{array}{l}\text { Índice sintético } \text { da } \\
\text { dimensão Educação, é um } \\
\text { dos } 3 \text { índices que compõem } \\
\text { o IDHM. É obtido através da } \\
\text { média geométrica do } \\
\text { Subíndice de frequência } \\
\text { escolar, com peso de } 2 / 3 \text {, e } \\
\text { do r Subíndicer de } \\
\text { escolaridade, com peso de } \\
1 / 3 \text {. }\end{array}$ & $\begin{array}{l}\text { Atlas } \\
\text { Brasil } \\
2010 \text { a } \\
2014\end{array}$ & Numérica \\
\hline
\end{tabular}

Fonte: Adaptado a partir de pesquisas no Atlas Brasil 2010 a 2014.

\subsubsection{Variáveis de Controle}

A relação entre as variáveis educacionais e a transparência foi controlada por variáveis econômicas relativas a desenvolvimento, renda, crescimento econômico, população e força política, que serviram de controles para identificar se, em condições socioeconômicas, a relação entre as variáveis de estudo sofrem alguma influência. 
Quadro 4. Variáveis de Controle

\begin{tabular}{|c|c|c|c|c|c|}
\hline \multicolumn{3}{|c|}{ Variável } & Descrição & Fonte & Cálculo \\
\hline X6 & $\begin{array}{l}\text { Renda per } \\
\text { capita }\end{array}$ & $\begin{array}{l}\text { Renda per } \\
\text { capita } \\
\text { média }\end{array}$ & $\begin{array}{l}\text { Razão entre o somatório da renda } \\
\text { de todos os indivíduos residentes } \\
\text { em domicílios particulares } \\
\text { permanentes e o número total } \\
\text { desses indivíduos. }\end{array}$ & $\begin{array}{c}\text { Atlas Brasil } \\
2010 \text { a } 2014\end{array}$ & Numérica \\
\hline $\mathrm{X} 7$ & GINI & $\begin{array}{l}\text { Índice de } \\
\text { Gini }\end{array}$ & $\begin{array}{l}\text { Mede o grau de desigualdade } \\
\text { existente na distribuição de } \\
\text { indivíduos segundo a renda } \\
\text { domiciliar per capita. Seu valor é } 0 \\
\text { quando não há desigualdade (a } \\
\text { renda domiciliar per capita de todos } \\
\text { os indivíduos tem o mesmo valor) e } \\
\text { tende a } 1 \text { à medida que a } \\
\text { desigualdade aumenta. O universo } \\
\text { de indivíduos é limitado àqueles } \\
\text { que vivem em domicílios } \\
\text { particulares permanentes. }\end{array}$ & $\begin{array}{l}\text { Atlas Brasil } \\
2010 \text { a } 2014\end{array}$ & Numérica \\
\hline X8 & População & População & População residente total & $\begin{array}{r}\text { Atlas Brasil } \\
2010 \text { a } 2014 \\
\end{array}$ & $\begin{array}{c}\text { Logaritmo } \\
\text { Natural }\end{array}$ \\
\hline X9 & PIB & $\begin{array}{l}\text { PIB per } \\
\text { capita }\end{array}$ & $\begin{array}{l}\text { Mede o resultado da soma da } \\
\text { remuneração dos fatores de } \\
\text { produção, isto é, remuneração dos } \\
\text { empregados, mais o rendimento } \\
\text { misto bruto, mais o excedente } \\
\text { operacional bruto, mais o total dos } \\
\text { impostos, líquidos de subsídios, } \\
\text { sobre a produção e importação. }\end{array}$ & IBGE & $\begin{array}{c}\text { Logaritmo } \\
\text { Natural }\end{array}$ \\
\hline $\mathrm{X} 10$ & $\begin{array}{l}\text { Força } \\
\text { Política }\end{array}$ & $\begin{array}{l}\text { Partidos } \\
\text { Políticos }\end{array}$ & $\begin{array}{l}\text { Mede os partidos políticos com } \\
\text { maior representatividade no poder } \\
\text { na esfera estadual }\end{array}$ & TSE & Dummy \\
\hline
\end{tabular}

Fonte: Adaptado a partir de pesquisas no Atlas Brasil 2010 a 2014, IBGE e TSE.

As variáveis de controle buscam identificar se a relação entre a educação e a transparência fiscal, quando analisadas com o fator renda, PIB, população, força política e o desenvolvimento humano da população, influenciam o modelo empírico, uma vez que, no estudo de Cruz et al. (2012), essas variáveis mostraram-se significativas com os níveis de transparência.

Para a definição da variável Força Política, numa amostra de 10 partidos políticos, dentro do universo de 135 observações de partidos políticos no poder, por estado, no período de 2010 a 2014, obtidos junto a base do Superior Tribunal Eleitoral - TSE, criou-se uma dummy para cada partido, a partir da representatividade de cada partido por estado, definida por meio de uma distribuição de frequência - Tabela 1 que identificou os partidos PMDB, PSB, PSDB e PT como os que aparecem mais vezes na amostra, indicando os partidos com maior representatividade e, consequentemente, com maior força política. A força política implica em maior transparência devido a competitividade eleitoral que exige mais e melhores informações, dados que os partidos políticos que concorrem com o governo ou dentro do próprio governo exigem mais transparência a fim de exercer o controle sobre as atividades governamentais (BEARFIELD; BOWMAN, 2017; CICATIELLO; SIMONE; GAETA, 2017). Além disso, manter os cidadãos informados sobre aplicação dos 
recursos públicos permite legitimidade aos políticos, evidenciado a influência política sobre os determinantes da transparência (MANES; BRUSCA; AVERSANO, 2018).

Tabela 1 - Distribuição dos Partidos Políticos

\begin{tabular}{l|c|c|c}
\hline \multicolumn{1}{c|}{ Partidos } & Frequência & Percentagem & Percentagem acumulada \\
\hline DEM & 8 & $5.93 \%$ & $5.93 \%$ \\
PDT & 1 & $0.74 \%$ & $6.67 \%$ \\
PFL & 1 & $0.74 \%$ & $7.41 \%$ \\
PMDB & 28 & $20.74 \%$ & $28.15 \%$ \\
PMN & 4 & $2.96 \%$ & $31.11 \%$ \\
PP & 1 & $0.74 \%$ & $31.85 \%$ \\
PPS & 2 & $1.48 \%$ & $33.33 \%$ \\
PSB & 27 & $20.00 \%$ & $53.33 \%$ \\
PSDB & 38 & $28.15 \%$ & $81.48 \%$ \\
PT & 25 & $18.52 \%$ & $100.00 \%$ \\
Total & $\mathbf{1 3 5}$ & $\mathbf{1 0 0 . 0 0 \%}$ & \\
\hline
\end{tabular}

\subsection{Modelo empírico}

Para analisar a relação entre o grau de transparência fiscal e o nível educacional, foi utilizada uma análise de regressão por Mínimos Quadrados Ordinários - MQO, com clusters de erro por estado, com o auxílio do software Stata e a amostra foi winsorizada a $1 \%$.

O modelo empírico adotado para realizar a análise dos dados, objetivando medir a relação entre a variável dependente Índice de Transparência Fiscal (ITF) com as Variáveis Educacionais dos Estados brasileiros para responder às hipóteses $\mathrm{H} 1$, que verificou se fatores educacionais têm relação positiva com os Índices de Transparência Fiscal dos estados brasileiros (ITF), foi o descrito pela seguinte equação (1).

Em que:

$$
\text { ITFit }=\beta_{0}+\sum_{i=1}^{5} \beta 1 . X i t+\text { Controlesit }+\varepsilon i t(1)
$$

ITF - Índice de Transparência Fiscal

$X_{1}-$ Anos de Estudo

$X_{2}-$ Frequência ao Ensino Superior

$X_{3}$ - Taxa de Ensino Médio Completo

$X_{4}$ - Taxa de Ensino Superior Completo

$X_{5}$ - Índice de Desenvolvimento Humano - Educação

Controle- Renda per Capita

Controle- Índice GINI

Controle - Força Política

Controle - PIB per Capita

Controle - População 


\section{Análise e discussão dos resultados 4.1 Estatística descritiva}

A Tabela 2 demonstra a estatística descritiva das variáveis do modelo. A variável Índice de Transparência Fiscal, que avalia a transparência fiscal dos portais dos estados brasileiros, indicando os estados com maior ou menor grau de transparência a partir de um ranking de notas, numa amostra com 135 observações, apresentou nota média entre os estados de 5,39. A média da variável, numa escala de notas que variam de 0 a 10 - indicando que quanto mais próximo de 10 melhor a transparência fiscal -, sugere que os estados brasileiros apresentam baixo grau de transparência, o que pode ser sustentado pelos estudos de Cruz et al. (2012); Ribeiro e Zuccolotto (2014) e Bernardo, Reis e Sediyama (2017), os quais afirmam que, apesar dos esforços legais e institucionais para sedimentar a transparência fiscal, ela ainda se encontra em estágio inicial de desenvolvimento no país.

Tabela 2: Estatística descritiva das variáveis quantitativas

\begin{tabular}{l|c|c|c|c|c|c|c|c}
\hline \multicolumn{1}{c|}{ Variáveis } & $\mathbf{n}$ & Média & $\begin{array}{c}\text { Desvio } \\
\text { padrão }\end{array}$ & Min & $\mathbf{2 5 \%}$ & Mediana & $\mathbf{7 5 \%}$ & Max \\
\hline $\begin{array}{l}\text { Índice de Transparência } \\
\text { Fiscal }\end{array}$ & 135 & 5,39 & 1,48 & 2,42 & 4,18 & 5,20 & 6,37 & 9,29 \\
\hline IDH - educação & 135 & 0,65 & 0,06 & 0,53 & 0,61 & 0,65 & 0,70 & 0,80 \\
\hline Anos de estudo & 135 & 8,49 & 1,06 & 6,28 & 7,63 & 8,63 & 9,22 & 10,88 \\
\hline $\begin{array}{l}\text { Frequência ao ensino } \\
\text { superior }\end{array}$ & 135 & 0,16 & 0,05 & 0,07 & 0,12 & 0,15 & 0,18 & 0,31 \\
\hline Taxa de ensino superior & 135 & 0,11 & 0,04 & 0,05 & 0,08 & 0,11 & 0,13 & 0,28 \\
\hline Taxa de ensino médio & 135 & 0,46 & 0,09 & 0,29 & 0,39 & 0,46 & 0,53 & 0,66 \\
\hline Renda per capita & 135 & 680,61 & 254,35 & 348,72 & 490,36 & 590,66 & 828,50 & 1606,40 \\
\hline Gini & 135 & 0,53 & 0,05 & 0,42 & 0,49 & 0,52 & 0,55 & 0,64 \\
\hline Força política & 135 & 0,87 & 0,33 & 0,00 & 1,00 & 1,00 & 1,00 & 1,00 \\
\hline PIB & 135 & 11,29 & 1,25 & 8,90 & 10,42 & 11,32 & 12,07 & 14,36 \\
\hline População & 135 & 15,22 & 1,04 & 13,03 & 14,71 & 15,12 & 15,97 & 17,51 \\
\hline
\end{tabular}

Fonte: Dados da pesquisa.

A taxa de Ensino Médio apresentou média de 0,46, sugerindo que, nos estados brasileiros, $46 \%$ da população têm o Ensino Médio completo, mas, conforme dados do MEC, relativos ao Indicador de Desenvolvimento da Educação Básica - IDEB, ano de 2015 - período que abrange a amostra estudada -, os estados não atingiram a meta de desenvolvimento estabelecida para essa faixa de ensino, refletindo baixo rendimento escolar que, de acordo com o Ministério da Educação, necessita de reformas para adequar-se aos padrões de boa educação (Portal Inep).

A Frequência ao Ensino Superior apresentou média de 0,16 entre os estados, indicando que $16 \%$ da população adulta, na faixa de 18 a 24 anos, frequentam o Ensino Superior. O Censo da Educação Superior no Brasil identificou que, dos anos de 2005 a 2014, o número de matriculados nessa faixa de ensino cresceu 75,7\%(Censo da Educação Superior / Portal Inep). O número de matriculados na educação superior, no ano de 2014, superou o quantitativo de 8 milhões de alunos matriculados, evidenciando um crescente aumento nessa faixa educacional no país (Portal Inep). 


\subsection{Teste de correlação e comparação de médias}

Do Teste de Correlação entre as variáveis, observou-se que a variável dependente ITF capturou relações com todas as variáveis educacionais.

Pode-se observar que as variáveis Taxa de Ensino Médio, Taxa de Ensino Superior e Desenvolvimento Humano - Educação, com 99\% de confiança, são significativas e possuem correlação mais fortes com a variável Índice de Transparência Fiscal do que com as demais variáveis educacionais usadas no modelo.

Com exceção da variável de controle Força Política, as demais variáveis do modelo mostraram associações positivas e significativas com a variável dependente ITF, sugerindo que, se os níveis de educação melhoram, também melhoram a transparência. Conforme Lindstedt e Naurin (2010), quanto maior o nível de educação, maior a capacidade das pessoas para acessarem e processarem as informações divulgadas.

Tabela 3 analisou o Teste de Diferença de Médias da variável ITF, considerando os estados acima da média amostral como de alta transparência fiscal e os abaixo da média amostral como de baixa transparência fiscal.

No nível de significância de 5\%, num intervalo de confiança de $95 \%$ para as duas amostras, constatou-se que os estados com alta transparência apresentam, em média, melhores níveis educacionais da população quando comparados com os estados com baixa transparência, conforme se observa da Tabela 3.

Observou-se também que as médias das variáveis educacionais foram maiores nos estados que apresentaram alta transparência fiscal, gerando evidências sumárias de que melhores indicadores educacionais estão associados positivamente à transparência fiscal, confirmando os estudos de Teixeira e Zuccolotto (2014); Tolbert, Mossberger, Macneal (2008) e Alcaraz, Navarro e Ortiz (2014).

Além disso, melhores indicadores educacionais sugerem a participação social mais efetiva, ao permitir melhor monitoramento das informações divulgadas, conforme afirmam Lindstedt e Naurin (2010), bem como sugerem o desenvolvimento de uma sociedade consciente de seus direitos e obrigações e que pressiona os governantes a divulgarem mais e melhor, segundo o mesmo entendimento de Ribeiro e Zuccolotto (2014). 
Tabela 3 - Diferença de média da amostra variável ITF

\begin{tabular}{|c|c|c|c|c|c|c|}
\hline \multirow{2}{*}{ Variáveis } & \multicolumn{2}{|c|}{$\begin{array}{c}\text { Transparência - ITF } \\
\text { Baixa }\end{array}$} & \multicolumn{2}{|c|}{$\begin{array}{c}\text { Transparência ITF } \\
\text { Alta }\end{array}$} & \multicolumn{2}{|c|}{$\begin{array}{l}\text { Diferença de } \\
\text { Médias }\end{array}$} \\
\hline & Média & $\begin{array}{l}\text { Desvio } \\
\text { padrão }\end{array}$ & Média & $\begin{array}{l}\text { Desvio } \\
\text { padrão }\end{array}$ & & P - Valor \\
\hline Anos de Estudos & 8,329 & 0,123 & 8,645 & 0,130 & $-0,315$ & $0,082^{*}$ \\
\hline Frequência ao Ensino Superior & 0,146 & 0,005 & 0,163 & 0,005 & $-0,016$ & $0,0384^{\star *}$ \\
\hline Taxa de Ensino Médio & 0,431 & 0,009 & 0,485 & 0,010 & $-0,054$ & $0,000^{\star \star \star}$ \\
\hline Taxa de Ensino Superior & 0,100 & 0,004 & 0,117 & 0,005 & $-0,016$ & $0,018^{* *}$ \\
\hline $\begin{array}{l}\text { Desenvolvimento Humano - } \\
\text { Educação }\end{array}$ & 0,636 & 0,006 & 0,672 & 0,008 & $-0,036$ & $0,000^{* * *}$ \\
\hline Renda per capita & 612,53 & 26,95 & 745,72 & 32,49 & $-133,19$ & $0,002^{* * *}$ \\
\hline GINI & 0,543 & 0,005 & 0,511 & 0,005 & 0,031 & $0,000^{* * *}$ \\
\hline Força Política & 0,893 & 0,038 & 0,855 & 0,042 & 0,038 & 0,4999 \\
\hline PIB & 10,720 & 0,132 & 11,837 & 0,140 & $-1,116$ & $0,000^{* * *}$ \\
\hline População & 14,805 & 0,123 & 15,221 & 0,110 & $-0,813$ & $0,000^{\star \star *}$ \\
\hline
\end{tabular}

Fonte: Dados da Pesquisa. Autoria própria

Nota: ${ }^{*}{ }^{* *} \mathrm{e}^{* \star *}$ representam coeficientes significativos a $10 \%, 5 \%$ e $1 \%$ respectivamente

\subsection{Regressão Linear Múltipla}

Para analisar a relação entre as variáveis educacionais com o grau de Transparência Fiscal dos estados brasileiros, foi utilizado um modelo de regressão lineares múltiplas, estimado pelo método de Mínimos Quadrados Ordinários. A Tabelas 5 apresentou os efeitos das variáveis educacionais sobre o nível de Transparência Fiscal dos estados para a variável ITF.

Tabela 4 - Regressão Linear Variável Transparência

\begin{tabular}{l|c|c|c}
\hline \multirow{2}{*}{ VARIÁVEIS } & \multicolumn{3}{c}{ INDICE DE TRANPARÉNCIA FISCAL - ITF } \\
\cline { 2 - 4 } & Coeficiente & Desvio - Padrão & P- Valor \\
\hline Anos de Estudos & -.0732953 & 6,600961 & 0.701 \\
\hline Frequência ao Ensino Superior & -7.328693 & 0,1887102 & 0.224 \\
\hline Taxa de Ensino Superior & 23.00643 & 5,885162 & $0.054^{*}$ \\
\hline Taxa de Ensino Médio & 9.597733 & 11,39699 & $0.016^{* *}$ \\
\hline $\begin{array}{l}\text { Desenvolvimento Humano - } \\
\text { Educação }\end{array}$ & $-10,38342$ & 3,737235 & 0.128 \\
\hline Renda per capita & -.0042166 & 0,0018086 & $0.028^{* *}$ \\
\hline GINI & -7.878977 & 3,809418 & $0.049^{* *}$ \\
\hline Força Política & -.1487639 & 0,192149 & 0.446 \\
\hline PIB & 1.373344 & 1,015753 & 0.188 \\
\hline População & -.7016229 & 1,108295 & 0.532 \\
\hline Constante & 9.357354 & 7,990242 & 0.252 \\
\hline No OBS & 135 & & \\
\hline $\mathbf{R}^{\mathbf{2}}$ & 0,4430 & & \\
\hline
\end{tabular}

Fonte: Dados da Pesquisa. Autoria própria.

Nota: ${ }^{\star \star} \mathrm{e}^{\star \star \star}$ representam coeficientes significativos a $5 \%$ e $1 \%$ respectivamente

Na Tabela 4, observou-se que o coeficiente de determinação ajustado R2 - que mede o nível de conformidade da variável ITF, que é explicada pelas variáveis educacionais - foi de $44,30 \%$. Isso significa que $44,30 \%$ da variação na variável 
Transparência Fiscal são elucidadas pelas variações acontecidas nas variáveis independentes analisadas no modelo.

A variável Taxa de Ensino Médio completo, com 95\% de confiança, revelou significância com os índices de transparência fiscal dos estados brasileiros, evidenciando uma relação positiva entre as variáveis, confirmando os estudos de que o nível educacional da população influencia os níveis de transparência fiscal dos entes públicos, por sugerir que a população mais instruída tende a cobrar mais e melhores resultados de seus governantes (CRUZ et al., 2012; TOLBERT; MOSSBERGER; MACNEAL, 2008; ALCARAZ; NAVARRO; ORTIZ, 2014). Essa análise leva à aceitação da hipótese $\mathrm{H} 1$ : fatores educacionais, como ferramenta do controle social, melhoram os indicadores de transparência fiscal.

A Taxa de Ensino Superior, com $90 \%$ de confiança, também se mostrou estatisticamente significativa para elucidar o grau de transparência dos estados, pois, conforme Piortrowski e Van Ryzin (2007), um diploma de nível superior habilita e capacita o cidadão ao entendimento da burocracia, dando-Ihe segurança para solicitar informações ao Governo, gerando demanda por mais transparência. Teixeira e Zuccolotto (2014) corroboram esse entendimento ao afirmarem que melhores condições educacionais levam ao desenvolvimento de uma sociedade consciente dos seus direitos e de suas obrigações, pressionando os governos a manterem os bons níveis dos serviços prestados.

Esse entendimento vai ao encontro dos achados de Ribeiro e Zuccolotto (2014), que afirmam que os governos com bons resultados na área das políticas sociais buscam constantemente validar sua boa administração, divulgando seus bons desempenhos. Além disso, pessoas com maior nível educacional tendem a ter melhores condições sociais e cobram mais de seus governantes a permanência dessa situação (RIBEIRO; ZUCCOLOTTO, 2014),

Sobre a regressão da variável ITF, observou-se que as variáveis de controle Renda per capita e o Índice GINI também revelaram relações com os graus de transparência fiscal, cujo resultado foi condizente aos estudos de Ribeiro e Zuccolotto (2014), segundo os quais fatores socioeconômicos, associados à renda e ao desenvolvimento social e humano, são capazes de proporcionar influência na transparência fiscal dos estados brasileiros.

Do resultado geral da Regressão Linear Múltipla, observou-se que a transparência fiscal dos estados brasileiros tem associação com os níveis educacionais da população, corroborando com a literatura para a qual os níveis educacionais aumentam a transparência fiscal, estreitando a relação entre cidadãos e estado, permitindo o monitoramento e o controle social (GLAESER; PONZETTO; SHLEIFER, 2007; DAHLUM, 2017; TOLBERT; MOSSBERGER; MACNEAL, 2008; ALT et al., 2006; LINDSTEDT; NAURIN, 2010; ALCARAZ; NAVARRO; ORTIZ,2014).

\section{Conclusões}

Esta pesquisa teve por foco o estudo da transparência fiscal como instrumento de acesso à informação, capaz de aproximar cidadãos e Governo e de possibilitar o controle e a participação social por meio de uma sociedade mais instruída e ciente dos seus direitos e obrigações. Essa premissa deu origem ao objetivo da pesquisa, qual seja o de identificar se os níveis de educação explicam o grau de transparência fiscal dos estados brasileiros. 
Para responder à hipótese proposta, elaborou-se um modelo empírico, analisado pela técnica de Regressão Linear Múltipla, que relacionou o Índice de Transparência Fiscal dos estados. O modelo teve por base avaliar a relação entre o Índice de Transparência Fiscal - ITF, com indicadores educacionais, disponíveis no Atlas do Desenvolvimento Humano no Brasil, dando-se ênfase aos indicadores relativos à população adulta apta ao exercício da cidadania.

O resultado da regressão linear entre as variáveis educacionais do modelo e a transparência fiscal revelou que, quando melhora o nível educacional da população, a relação com o nível de transparência mostra-se positiva. Esses resultados confirmam a literatura consultada, que afirma que maiores níveis educacionais estimulam a cobrança por mais informações, estreitando a relação entre cidadãos e Estado, aumentando o grau de transparência.

Os resultados demonstrados neste estudo revelaram a necessidade prática de investimentos em políticas públicas educacionais efetivas que melhorem a qualidade do ensino, com o objetivo de capacitar os cidadãos ao exercício do controle social, evitando-se o mau uso e o desperdício de recursos públicos. Para a academia, os resultados apresentados mostraram a relevância da educação como atributo necessário ao perfil dos cidadãos para a compreensão da transparência fiscal e a consequente participação no processo democrático do país, deixando em evidência a variáveis educacionais como causa eficaz dos possíveis determinantes da Transparência Fiscal.

Como limitação do estudo, destaca-se o baixo nível de observações da amostra estudada, não pela comodidade em escolher uma amostra pequena, mas pela falta de dados disponíveis, o que poderia gerar erros de estimativas no modelo.

Para estudos futuros, sugere-se a avaliação da relação entre os níveis de educação e a transparência fiscal por estado dentro de uma mesma região geográfica, a fim de verificar se, em ambientes socioeconômicos semelhantes, as variáveis se comportam de forma análoga e se isso justifica o resultado do conjunto e possibilita comparação entre regiões

\section{Referências}

ABREU, W. M.; GOMES, R. C.; ALFINITO, S. Transparência fiscal explica desenvolvimento social nos estados brasileiros? Sociedade, Contabilidade e Gestão, v. 10, n. 2, p. 54-69, 2015.

ALCARAZ-QUILES, F. J.; NAVARRO-GALERA, A.; ORTIZ-RODRÍGUEZ, D. Factors influencing the transparency of sustainability information in regional governments: an empirical study. Journal of Cleaner Production, v. 82, p. 179-191, 2014.

ALT, J. E.; LASSEN, D. D.; ROSE, S. The causes of fiscal transparency: evidence from the US states. IMF Staff papers, p. 30-57, 2006.

ARAUJO, J. F. F. E.; TEJEDO-ROMERO, F. Local government transparency index: determinants of municipalities' rankings. International Journal of Public Sector Management, v. 29, n. 4, p. 327-347, 2016. 
ATLAS do Desenvolvimento Humano no Brasil. 2013. Disponível em: <http://atlasbrasil.org.br/2013/>. Acesso em: 5 fev. 2018.

BAIRRAL, M. A. C.; SILVA, A. H. C.; ALVES, F. J. D. S. Transparência no setor público: uma análise dos relatórios de gestão anuais de entidades públicas federais no ano de 2010.Revista de Administração Pública, v. 49, n. 3, p. 643-675, 2015.

BARROS, A. T. Educação e legislação: desafios para o aprendizado político e a cultura democrática. Educação \& Sociedade, v. 37, n. 136, 2016.

BEARFIELD, D.A.; BOWMAN, A.O.M. Can you find it on the web? An assessment of municipal e-government transparency. The American Review of Public Administration, 47.2: 172-188, 2017.

BERNARDO, J. S.; REIS, A. O.; SEDIYAMA, G. A. S. Características Explicativas do Nível de Transparência na Administração Pública Municipal. Revista Ciências Administrativas, v. 23, n. 2, p. 277-292, 2017.

BERTOT, J. C.; JAEGER, P. T.; GRIMES, J. M. Using ICTs to create a culture of transparency: E-government and social media as openness and anti-corruption tools for societies. Government information quarterly, v. 27, n. 3, p. 264-271, 2010.

BORGES, E. F.; PEREIRA, J. M. Educação fiscal e eficiência pública: um estudo das suas relações a partir da gestão de recursos municipais. Revista de Educação e Pesquisa em Contabilidade (REPeC), v. 8, n. 4, 2014,

BRASIL. Lei no 9.394, de 20 de dezembro de 1996. Estabelece as diretrizes e bases da educação nacional. Diário Oficial [da República Federativa do Brasil], Brasília, DF, v. 134, n. 248, 23 dez. 1996.Seção I, p. 27834-27841.

Lei complementar n-101, de 4 de maio de 2000. Estabelece normas de finanças públicas voltadas para a responsabilidade na gestão fiscal e dá outras providências. Disponível em: https://www.planalto.gov.br/. Acesso em: 26 mar. 2018.

. MINISTÉRIO DA EDUCAÇÃO. (Org.). Secretária executiva do MEC aponta metas para ensino médio e defende flexibilização. 2016. Disponível em: <http://portal.mec.gov.br/component/tags/tag/34167>. Acesso em: 01 mar. 2018.

CELLA, R. S.; ZANOLLA, E. A Lei de Benford e a Transparência: Uma Análise das Despesas Públicas Municipais. Brazilian Business Review, v. 15, n. 4, p. 331-347, 2018.

CICATIELLO, Lorenzo; SIMONE, Elina de; GAETA, Giuseppe Lucio. Political determinants of fiscal transparency: a panel data empirical investigation. Economics of Governance, 18.4: 315-336, 2017

CORBARI, E. C. Accountability e controle social: desafio à construção da cidadania. Negócios, v. 1, n. 2, 2014. 
CRUZ, C. F.; FERREIRA, A. C. S.; SILVA, L. M.; MACEDO, M. A. S. Transparência da gestão pública municipal: um estudo a partir dos portais eletrônicos dos maiores municípios brasileiros. Revista de Administração Pública, v. 46, n. 1, p. 153-176, 2012.

CRUZ, N. F. et al. Measuring local government transparency. Public Management Review, v.18, n. 6, p. 866-893, 2016.

CUCCINIELLO, M.; PORUMBESCU, G. A.; GRIMMELIKHUIJSEN, S. 25 Years of Transparency Research: Evidence and Future Directions. Public Administration Review, v. 77, n. 1, p. 32-44, 2017.

DAHLUM, S.; KNUTSEN, C. H. Do Democracies Provide Better Education? Revisiting the Democracy-Human Capital Link. World Development, v. 94, p. 186199, 2017.

FIGUEIREDO, V. S.; SANTOS, W. J. L. Transparência e controle social na administração pública. Temas de Administração Pública, v. 8, n. 1, 2013.

GLAESER, E. L.; PONZETTO, G. AM; SHLEIFER, A. Why does democracy need education? Journal of economic growth, v. 12, n. 2, p. 77-99, 2007.

GRIMMELIKHUIJSEN, Stephan G.; MEIJER, Albert J. Effects of transparency on the perceived trustworthiness of a government organization: Evidence from an online experiment. Journal of Public Administration Research and Theory, 24.1: 137-157, 2012.

GUILLAMÓN, M.-D.; BASTIDA, F.; BENITO, B. The determinants of local government's financial transparency. Local Government Studies, v. 37, n. 4, p. 391406, 2011.

ÍNDICE DE TRANSPARÊNCIA. 2014. Disponível em: $<$ https://indicedetransparencia.com/>. Acesso em: 3 fev. 2018.

INSTITUTO NACIONAL DE ESTUDOS E PESQUISAS EDUCACIONAIS ANÍSIO TEIXEIRA (INEP). (Org.). Notas estatística do censo superior. 2015. Disponível em:<http://download.inep.gov.br/educacao_superior/censo_superior/documentos/20 15/Notas_Estatisticas_Censo_Superior_2015.pdf>. Acesso em: 23 jan. 2018.

JAHNS, F. T.; RAUPP, F. M. Transparência do Poder Executivo dos Estados Brasileiros. Revista Universo Contábil, v. 12, n. 3, p. 65-72, 2016.

LIMA, C. H. S.; CRUZ, A. P. C.; MACHADO, D. G.; QUINTANA, A. C. Portal da transparência: um estudo comparativo entre os municípios de porto alegre e pelotas. Contexto - Revista do Programa de Pós-Graduação em Controladoria e Contabilidade da UFRGS, v. 15, n. 30, p. 94-110, 2015.

LINDSTEDT, C.; NAURIN, D. Transparency is not enough: Making transparency effective in reducing corruption. International political Science review, v. 31, n.3, p. 301-322, 2010. 
MANES, Francesca Rossi; BRUSCA, Isabel; AVERSANO, Natalia. Financial sustainability as a driver for transparency and E-Democracy: A comparative study in Italian and Spanish local governments. International Journal of Public Administration, 41.1: 22-33, 2018.

MEIJER, Albert. Understanding the complex dynamics of transparency. Public Administration Review, 73.3: 429-439, 2013.

MEIJER, Albert. Government transparency in historical perspective: from the ancient regime to open data in the Netherlands. International Journal of Public Administration, 38.3: 189-199, 2015

MONTES, Gabriel Caldas; BASTOS, Júlio Cesar Albuquerque; OLIVEIRA, Ana Jordânia de. Fiscal transparency, government effectiveness and government spending efficiency: Some international evidence based on panel data approach. Economic Modelling, 79: 211-225, 2019.

MOTA, B. F.; DINIZ, J. A.; SANTOS, L. C. A Estrutura Orçamentária como Determinante do Nível de Transparência Fiscal. Contabilidade, Gestão e Governança, v. 20, n. 2, p. 293-313, 2017.

ONUBR (Brasil) (Org.). Brasil precisa ampliar investimentos na educação de jovens e adultos, alertam especialistas. 2017. Disponível em: $<$ https://nacoesunidas.org/brasil-precisa-ampliar-investimentos-na-educacao-dejovens-e-adultos-alertam-especialistas/>. Acesso em: 20 out. 2017.

PAIVA, C.P.R.; ZUCCOLOTTO, R. Índice de transparência fiscal das contas públicas dos municípios obtidos em meios eletrônicos de acesso público. IN: ENCONTRO DA ANPAD, 33., São Paulo, 2009. Anais... Enanpad, 2009

PIOTROWSKI, Suzanne J.; VAN RYZIN, Gregg G. Citizen attitudes toward transparency in local government. The American Review of Public Administration, v. 37, n. 3, p. 306-323, 2007.

PLATT NETO, O. A.; CRUZ, F.; ENSSLIN, S. R.; ENSSLIN, L. Publicidade e transparência das contas públicas: obrigatoriedade e abrangência desses princípios na administração pública brasileira. Contabilidade Vista \& Revista, v. 18, n. 1, p. 7594, 2007.

PORUMBESCU, Gregory. Linking transparency to trust in government and voice. The American Review of Public Administration, 47.5: 520-537, 2017.

RIBEIRO, C. P. P.; ZUCCOLOTTO, R. A face oculta do Leviatã: transparência fiscal nos municípios brasileiros e suas determinantes socioeconômicas e fiscais. Enfoque Reflexão Contábil, v. 33, n. 1, p. 37-52, 2014.

RODRIGUES, N. Educação: da formação humana à construção do sujeito ético. Educação e Sociedade, p. 22, n. 76, p. 232-257, 2001. 
SIMONE, Elina de; GAETA, Giuseppe Lucio; MOURÃO, Paulo Reis. The Impact of Fiscal Transparency on Corruption: An Empirical Analysis Based on Longitudinal Data. The BE Journal of Economic Analysis \& Policy, 17.4., 2017

SOL, D. A. The institutional, economic and social determinants of local government transparency. Journal of Economic Policy Reform, v. 16, n. 1, p. 90-107, 2013.

TEJEDO-ROMERO, Francisca; ARAUJO, Joaquim Filipe Ferraz Esteves de. Determinants of local governments' transparency in times of crisis: evidence from municipality-level panel data. Administration \& society, , 50.4: 527-554, 2018.

TOLBERT, C. J.; MOSSBERGER, K.; MCNEAL, R. Institutions, policy innovation, and $\mathrm{E}$ - Government in the American States. Publica administration review, v. 68, n. 3, p. 549-563, 2008.

ZUCCOLOTTO, R.; TEIXEIRA, M. A. C. As Causas da Transparência Fiscal: Evidências nos Estados Brasileiros. Revista Contabilidade \& Finanças - USP, v. 25, n. 66, p. 242-254, 2014.

- Gestão Social, Democracia, Representação e Transparência: Evidências nos Estados Brasileiros. Revista de Ciências da Administração, v. 17, n. Ed. Especial, p. 79-90, 2015.

- Transparência Orçamentária: Razões do Descompasso entre os

Estados Brasileiros. Organizações \& Sociedade, v. 24, n. 82, p. 390-411, 2017. 